\title{
Chemical Intolerance in Primary Care Settings: Prevalence, Comorbidity, and Outcomes
}

David A. Katerndabl, $M D, M A^{1}$

Iris R. Bell, $M D, P b D^{2}$

Raymond F. Palmer, $\mathrm{PbD}^{1}$

Claudia S. Miller, MD, MS

'University of Texas Health Science Center at San Antonio, San Antonio, Texas

${ }^{2}$ University of Arizona College of Medicine, Tucson, Arizona
Conflicts of interest: authors report none.

\section{CORRESPONDING AUTHOR}

David Katerndahl, MD

Family \& Community Medicine

University of Texas Health Science Center

at San Antonio

7703 Floyd Curl Dr

San Antonio, TX 78229-3900

katerndahl@uthscsa.edu

\begin{abstract}
PURPOSE This study extends previous community-based studies on the prevalence and clinical characteristics of chemical intolerance in a sample of primary care clinic patients. We evaluated comorbid medical and psychiatric disorders, functional status, and rates of health care use.

METHODS A total of 400 patients were recruited from 2 family medicine clinic waiting rooms in San Antonio, Texas. Patients completed the validated Quick Environmental Exposure and Sensitivity Inventory (QEESI) to assess chemical intolerance; the Primary Care Evaluation of Mental Disorders (PRIME-MD) screen for possible psychiatric disorders; the Dartmouth-Northern New England Primary Care Cooperative Information Project (Dartmouth COOP) charts for functional status; and the Healthcare Utilization Questionnaire.

RESULTS Overall, $20.3 \%$ of the sample met criteria for chemical intolerance. The chemically intolerant group reported significantly higher rates of comorbid allergies and more often met screening criteria for possible major depressive disorder, panic disorder, generalized anxiety disorder, and alcohol abuse disorder, as well as somatization disorder. The total number of possible mental disorders was correlated with chemical intolerance scores $(P<.001)$. Controlling for demographics, patients with chemical intolerance were significantly more likely to have poorer functional status, with trends toward increased medical service use when compared with non-chemically intolerant patients. After controlling for comorbid psychiatric conditions, the groups differed significantly only regarding limitations of social activities.
\end{abstract}

CONCLUSIONS Chemical intolerance occurs in 1 of 5 primary care patients yet is rarely diagnosed by busy practitioners. Psychiatric comorbidities contribute to functional limitations and increased health care use. Chemical intolerance offers an etiologic explanation. Symptoms may resolve or improve with the avoidance of salient chemical, dietary (including caffeine and alcohol), and drug triggers. Given greater medication intolerances in chemical intolerance, primary care clinicians could use the QEESI to identify patients for appropriate triage to comprehensive nonpharmacologic care.

Ann Fam Med 2012;10:357-365. doi:10.1370/afm.1346.

\section{INTRODUCTION}

$\mathrm{B}$ etween $13 \%$ and $33 \%$ of people in various populations report considering themselves to be "unusually" sensitive to certain common environmental chemicals, such as cleaning products, tobacco smoke, perfumes, pesticides, new carpet, and car exhaust..$^{1-7}$ This condition, known as chemical intolerance, ${ }^{*}$ is the hallmark of multiple chemical sensitivity (MCS), also known as multiple chemical intolerance or idiopathic environ-

*Semantics in this area are a minefield. In this article, we use chemical intolerance to describe the loss of prior, natural tolerance to common foods and drugs that occurs in a subset of individuals, sometimes after an initial exposure, such as to pesticides or a "sick building." Various authors have used toxicant-induced loss of tolerance 
mental intolerance. Chemical intolerance has a prevalence of $2 \%$ to $13 \%$ in population-based surveys. ${ }^{1,2}$ Symptoms are typically multisystem, that is, affecting cognitive, affective, musculoskeletal, gastrointestinal, genitourinary, and cardiovascular systems. ${ }^{8,9}$ Despite its relatively high prevalence in nonclinical samples, the diagnosis and etiology of chemical intolerance remain controversial and understudied. Skeptics and proponents often frame the debate in a dualistic manner, claiming that chemical intolerance is either completely psychogenic or completely toxicogenic; however, accumulating data suggest that a more nuanced, multifactorial psychobiological process underlies the condition.

Apart from the debate over causality, chemical intolerance holds particular relevance for primary care clinicians. Patients who are chemically intolerant use health care services at increased rates (making an average of 23.3 visits to a medical professional per year). ${ }^{10}$ In addition, chemical intolerance is associated with poor quality of life and functional impairments leading to loss of employment and socioeconomic hardships. ${ }^{11-13}$ It is also associated with more medication prescriptions, ${ }^{3}$ greater use of physicians and hospitals after exposures, ${ }^{12}$ and more visits to environmental specialists. ${ }^{14}$ Nonetheless, coordinated multidisciplinary care substantially reduces health care costs in this population. ${ }^{15}$

Previous studies show that persons meeting various criteria for MCS or the less severe, more common chemical intolerance also have increased rates of certain medical and psychiatric conditions. Comorbid diagnoses include heart problems ${ }_{1}{ }^{16}$ bronchitis ${ }_{1}^{16}$ asthma, ${ }_{1}^{16}$ pneumonia ${ }_{1}^{16}$ rhinitis, ${ }^{5,6}$ sinusitis, ${ }^{5}$ hypothyroidism and other autoimmune diseases, ${ }^{5,17}$ irritable bowel syndrome, ${ }^{5}$ migraine, ${ }^{5}$ fibromyalgia, ${ }^{10,18-20}$ and chronic fatigue syndrome. ${ }^{10,18-20}$ Family histories in persons having high scores for chemical intolerance show an increased prevalence of heart disease, diabetes mellitus, asthma, and rhinitis, ${ }_{1}^{16}$ as well as alcohol and drug abuse. ${ }^{21,22}$

Other studies report associations with panic disorder, $_{1}^{23,24}$ major depression, ${ }_{1}^{13,14,25}$ and childhood hyperactivity. ${ }^{26,27}$ A substantial subset of affected individuals also report multiple food intolerances, ${ }^{28-30}$ and several studies have demonstrated food triggers in a subset of children with attention-deficit/hyperactivity disorder (ADHD), migraine, and epilepsy, ${ }^{31-36}$ as well as adults with schizophrenia. ${ }^{37,38}$

Although some investigators label these patients as having somatoform spectrum disorder, ${ }_{1}^{11,39,40}$ the mean age of onset is typically older than 30 years, ${ }^{12}$ a finding that is inconsistent with the diagnostic criterion requirement for the earlier age of onset in the Diagnostic and Statistical Manual of Mental Disorders (4th Edition) (DSM-IV) for classic somatization disorder. ${ }^{41}$ Apart from etiology, elevated levels of subjective mental distress (eg, somatization, anxiety, depression) are a major factor in increasing health care use across diagnoses in the general population. ${ }^{42,43}$ Persons with chemical intolerance score higher on scales measuring somatization, anxiety, and depression, ${ }^{5,17}$ although the scores on these psychiatric dimensions account for only a small portion of variance in total chemical intolerance scores outside clinical settings. ${ }^{6,44}$ Taken together, the evidence suggests that chemical intolerance may be an important yet unrecognized contributor to the clinical presentation and use patterns of patients in primary care. ${ }^{45}$

The purposes of our study were to assess the prevalence of chemical intolerance and comorbid medical and mental disorders among primary care patients, and to use standardized instruments to evaluate these patients' functional status and health care use.

\section{METHODS}

\section{Participants}

We recruited 400 adult patients (aged $\geq 18$ years) from the waiting rooms of 2 primary care clinics in San Antonio, Texas, who were seeking care for nonacute conditions. The University Health Center-Downtown serves a low-income, predominantly Hispanic population, whereas the Leonard G. Paul Family Health Center serves a predominantly middle-class Hispanic and nonHispanic white population. Patients were approached in the waiting room after signing in, by seeking the most recent patient to register, no eligible adult patient refused participation. On verbally agreeing to participate in a study about sensitivity to chemicals, patients gave written informed consent. Participants received monetary compensation $(\$ 5)$ for participation.

\section{Instruments}

All patients completed a questionnaire having 90 selfreport items in either English or Spanish in 20 minutes before seeing the physician. The questions covered demographics, chemical intolerance, mental disorders, functional status, and health care use. The Hollingshead scale measured socioeconomic status (SES). ${ }^{46}$

(TILT) and idiopathic environmental intolerance (IEI) to describe this phenomenon, depending on whether the intolerances began after an identifiable initiating event. The advantage of the term intolerance is that it presumes no particular mechanism. In contrast, researchers in addiction and neurology use sensitization (eg, neural sensitization or time-dependent sensitization) to describe heightened responses after repeated exposures to a drug or chemical. On the other hand, allergists and immunologists have objected to using the word sensitization to describe the heightened responses to chemicals in these individuals in the absence of evidence that their responses are immune mediated (ie, mediated by lgE). In this article, we use chemical intolerance and multiple chemical sensitivity interchangeably because the literature we cite uses both terms, and the clinical picture appears to be the same, namely, multisystem symptoms and adverse responses to structurally unrelated chemicals, foods, and drugs. Further, this phenomenon is widely reported under multiple diagnostic labels in the United States and more than a dozen industrialized nations. 
The Quick Environmental Exposure and Sensitivity Inventory (QEESI), a validated, 50-item, selfadministered instrument with high sensitivity and specificity for differentiating individuals with chemi$\mathrm{cal}$ intolerance from the general population, gauged chemical intolerance. ${ }^{29}$ It has 4 scales-symptom severity, intolerance to inhaled chemicals (eg, diesel exhaust, fragrance, cleaning products), intolerance to other substances (eg, foods, medications, alcoholic beverages), and life impact-as well as a masking index, which is a measure of ongoing chemical exposures. Patients were defined as having chemical intolerance if they had a score of 40 or greater on both the chemical intolerance scale (range, 0-100) and the symptom severity scale (range, 0-100).

The Primary Care Evaluation of Mental Disorders (PRIME-MD) Patient Questionnaire screened for symptoms of mental disorders within the past month, including panic disorder, generalized anxiety disorder, major depressive disorder, alcohol abuse disorder, and somatization disorder. Its 25 items show both construct and concurrent validity. ${ }^{47}$

The Dartmouth-Northern New England Primary Care Cooperative Information Project (Dartmouth COOP) charts' 8 pictograph scales (scored 1 to 5 , where $5=$ greatest impairment) assessed functional status within the past month. The COOP charts provide more valid assessments for groups that are culturally diverse, have low literacy rates, or both. In addition to acceptable test-retest reliability (0.42-0.98), the COOP charts have good intraclass correlation coefficients $(0.50-0.98)$ as well as concurrent and construct validity. ${ }^{48}$

Finally, the Health Care Utilization Questionnaire evaluated use over the previous 2 months. ${ }^{49}$ This 8-item instrument asks individuals to report the number of visits they made to emergency settings (emergency department, minor emergency room, ambulance), physician offices, and mental health settings. Previous work has shown that patients can accurately recall their health care use over the past 2 months. ${ }^{50}$ Individuals also report how many times they were hospitalized in the preceding year.

\section{Analysis}

Associations between chemical intolerance and possible mental disorders were assessed using odds ratios. To adjust for the possible impact of other factors on functional status and health care use, we used multivariate analysis of variance (MANOVA) tests, first adjusting for demographic variables (Model 1) and then adjusting for both demographic variables and possible mental health disorders (Model 2). We used $P \leq .05$ as indicating significance, with $P \leq .10$ considered a trend.

\section{RESULTS}

Participants were middle aged on average, with a mean age of 47.4 years (SD, 14.7). Table 1 presents other demographics for the sample. Almost two-thirds of patients were women. One-third had less than a high school education. The majority of the sample fell largely into low-income and Hispanic groups.

Overall, 81 patients $(20.3 \%)$ met criteria for chemical intolerance. The prevalence of chemical intolerance was related to social class: it was $9.1 \%$ among patients in Class I/II (highest SES status), 13.7\% among those in Class III/IV, and $24.7 \%$ among those in Class V (lowest SES status) $\left(\chi^{2}=8.20, P=.04\right)$. Patients who met criteria for chemical intolerance rated the severity of their intolerances or adverse reactions to medications, medical procedures, or medical materials significantly higher than did those without chemical intolerance $($ mean $=4.41$ vs $1.87, t=-5.42, P$ $<.001)$. Of the 81 patients who met criteria for chemical intolerance, only 19 (24\%) reported having previously received this diagnosis.

Table 2 gives odds ratios for personal and family histories of self-reported medical and psychiatric conditions. In general, patients with chemical intolerance reported increased rates of most of the conditions

\begin{tabular}{|lc|}
\hline \multicolumn{2}{|c|}{ Table 1. Patient Characteristics (N $=400)$} \\
\hline Characteristic & $\begin{array}{c}\text { Patients, } \\
\text { No. (\%) }\end{array}$ \\
\hline Clinic & \\
University Health Center-Downtown & $270(68)$ \\
Leonard G. Paul Family Health Center & $130(33)$ \\
Sex & \\
Male & $148(37)$ \\
Female & $252(63)$ \\
Ethnicity & \\
Hispanic & $343(86)$ \\
Non-Hispanic white & $57(14)$ \\
Education & \\
Less than high school & $125(32)$ \\
High school graduate & $102(26)$ \\
Some college & $168(43)$ \\
Income & \\
$<\$ 20,000$ & $205(68)$ \\
$\$ 20,000-\$ 40,000$ & $68(23)$ \\
$>\$ 40,000$ & $29(7)$ \\
Social class & \\
I & $3(1)$ \\
II & $19(5)$ \\
III & $87(22)$ \\
IV & $51(13)$ \\
V & $235(60)$ \\
\hline a Missing excluded. & \\
b Based on Hollingshead and Redlich. ${ }^{46}$ Class I is highest socioeconomic status. \\
\hline
\end{tabular}


Table 2. Odds of a Personal History and Family History of Conditions by Chemical Intolerance Status

\begin{tabular}{|c|c|c|c|c|c|c|}
\hline \multirow[b]{2}{*}{ Condition } & \multicolumn{3}{|c|}{ Personal Historya } & \multicolumn{3}{|c|}{ Family History ${ }^{a}$} \\
\hline & $\begin{array}{c}\text { Chemically } \\
\text { Intolerant } \\
(n=81)\end{array}$ & $\begin{array}{l}\text { Chemically } \\
\text { Tolerant } \\
(\mathrm{n}=319)\end{array}$ & $\begin{array}{l}\text { Odds Ratio } \\
(95 \% \mathrm{Cl})\end{array}$ & $\begin{array}{c}\text { Chemically } \\
\text { Intolerant } \\
(n=81)\end{array}$ & $\begin{array}{c}\text { Chemically } \\
\text { Tolerant } \\
(\mathrm{n}=319)\end{array}$ & $\begin{array}{l}\text { Odds Ratio } \\
(95 \% \mathrm{Cl})\end{array}$ \\
\hline Asthma & $14(17)$ & $34(11)$ & $1.75(0.89-3.45)$ & $22(27)$ & $59(19)$ & $1.64(0.93-2.89)$ \\
\hline Allergies & $43(53)$ & $129(40)$ & $1.67(1.02-2.72)^{b}$ & $36(44)$ & $132(41)$ & $1.13(0.69-1.85)$ \\
\hline Autism & $1(1.2)$ & $1(0.3)$ & $3.98(0.25-64.24)$ & $2(3)$ & $8(3)$ & $0.98(0.21-4.73)$ \\
\hline Multiple sclerosis & $0(0)$ & $2(0.6)$ & - & $1(1)$ & $7(2)$ & $0.56(0.07-4.59)$ \\
\hline Arthritis & $27(33)$ & $75(24)$ & $1.63(0.96-2.76)$ & $31(38)$ & $97(30)$ & $1.42(0.85-2.36)$ \\
\hline Diabetes & $22(27)$ & $63(20)$ & $1.52(0.86-2.66)$ & $39(48)$ & $122(38)$ & $1.50(0.92-2.45)$ \\
\hline Gastrointestinal disorder & $14(17)$ & $54(17)$ & $1.03(0.54-1.96)$ & $21(26)$ & $31(10)$ & $3.25(1.75-6.04)^{b}$ \\
\hline Mood disorder & $44(54)$ & $64(20)$ & $4.74(2.83-7.94)^{\mathrm{b}}$ & $31(38)$ & $56(18)$ & $2.92(1.71-4.96)^{b}$ \\
\hline Chemical intolerance & $19(24)$ & $24(8)$ & $3.77(1.94-7.30)^{b}$ & $16(20)$ & $24(8)$ & $3.03(1.52-6.02)^{b}$ \\
\hline Systemic lupus erythematosus & $3(4)$ & $5(2)$ & $2.42(0.57-10.33)$ & 7 (9) & $9(3)$ & $3.26(1.18-9.03)^{b}$ \\
\hline
\end{tabular}

Table 3. Odds of Symptoms of Mental Disorders by Chemical Intolerance Status

\begin{tabular}{lccc}
\hline & $\begin{array}{c}\text { Chemically } \\
\text { Intolerant, } \\
\text { No. (\%) } \\
\mathbf{( n = 8 1 )}\end{array}$ & $\begin{array}{c}\text { Chemically } \\
\text { Tolerant, } \\
\text { No. (\%) } \\
(\mathbf{n}=\mathbf{3 1 9 )}\end{array}$ & $\begin{array}{c}\text { Odds Ratio } \\
\mathbf{( 9 5 \% ~ C I )}\end{array}$ \\
Disorder & $69(85)$ & $106(33)$ & $11.55(6.00-22.26)^{\mathrm{b}}$ \\
\hline Major depressive disorder & $63(78)$ & $67(21)$ & $13.16(7.30-23.73)^{\mathrm{b}}$ \\
Generalized anxiety disorder & $44(54)$ & $53(17)$ & $5.97(3.52-10.11)^{\mathrm{b}}$ \\
Panic disorder & $30(37)$ & $63(20)$ & $2.39(1.41-4.06)^{\mathrm{b}}$ \\
Alcohol abuse disorder & $74(91)$ & $218(68)$ & $4.90(2.18-11.01)^{\mathrm{b}}$ \\
Somatization disorder & \multicolumn{4}{l}{} \\
\hline a Symptoms of the disorder were assessed with the Primary Care Evaluation of Mental Disorders Patient \\
Questionnaire. \\
b Significant odds ratio.
\end{tabular}

\section{Figure 1. Prevalence of Chemical Intolerance vs Number of Possible Mental Disorders}

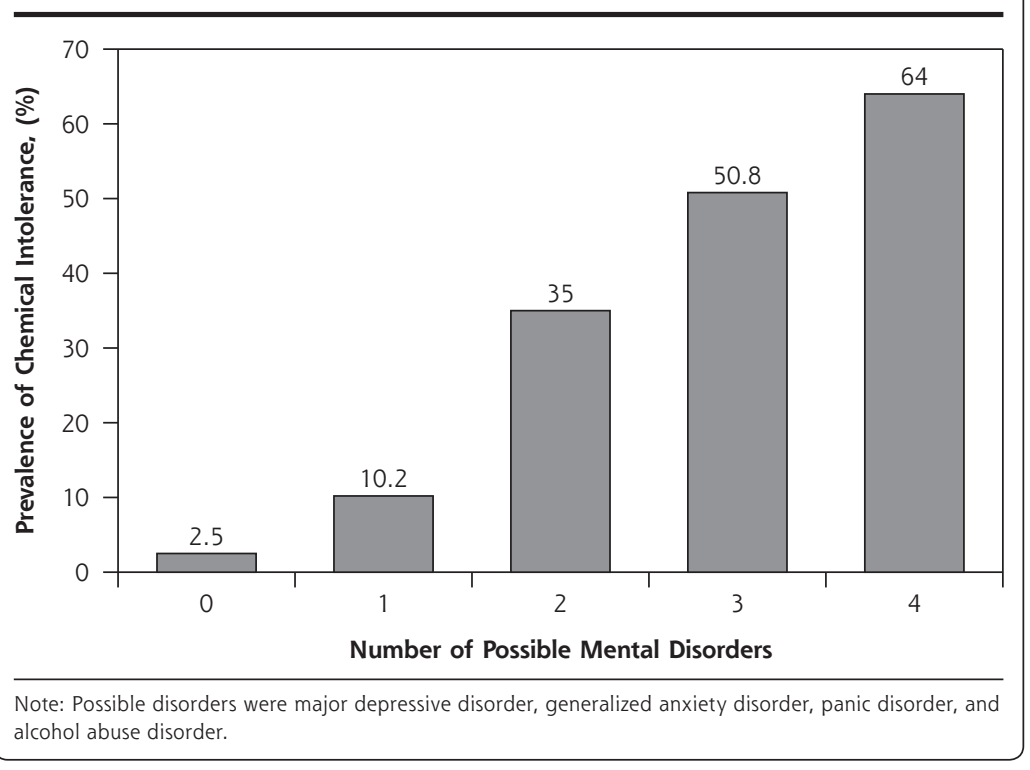

on the list. Also, they were more likely to report family histories of the same disorders, but only the family histories of gastrointestinal disorders, mood disorders, chemical intolerance, and systemic lupus erythematosus were significantly more common than in the group without chemical intolerance.

The 4 mental disorders previously linked with chemical intolerance (major depressive disorder, panic disorder, generalized anxiety disorder, alcohol abuse disorder) were significantly associated with chemical intolerance status (Table 3). In fact, Figure 1 shows that there was a linear relationship between the number of possible mental disorders and the prevalence of chemical intolerance. Similar to what has been found in earlier studies, PRIME-MD screening symptoms of possible somatization disorder were also significantly related to chemical intolerance.

Before controlling for demographics and comorbid psychiatric conditions, chemical intolerance was significantly associated with poorer functional status in all 8 areas of functioning, with trends toward significance for use of emergency services, medical specialists, and total ambulatory services, as well as hospitalization. In MANOVA controlling for demographic variables (Model 1), 
Table 4. Functional Status and Health Care Use by Chemical Intolerance Status

\begin{tabular}{|c|c|c|c|c|c|c|}
\hline \multirow[b]{2}{*}{ Variable } & \multicolumn{3}{|c|}{ Model $1^{a}$} & \multicolumn{3}{|c|}{ Model $2^{b}$} \\
\hline & $\begin{array}{l}\text { Chemically } \\
\text { Intolerant } \\
(n=81)\end{array}$ & $\begin{array}{c}\text { Chemically } \\
\text { Tolerant } \\
(n=319)\end{array}$ & F ( $P$ Value) & $\begin{array}{l}\text { Chemically } \\
\text { Intolerant } \\
(n=81)\end{array}$ & $\begin{array}{c}\text { Chemically } \\
\text { Tolerant } \\
(n=319)\end{array}$ & F ( $P$ Value) \\
\hline \multicolumn{7}{|l|}{$\begin{array}{l}\text { Limitations in functional } \\
\text { status in past monthc }\end{array}$} \\
\hline Daily activities & 3.17 & 2.27 & $39.31(<.001)$ & 2.69 & 2.39 & $3.61(.058)$ \\
\hline Social activities & 3.02 & 1.95 & $54.60(<.001)$ & 2.46 & 2.09 & $5.42(.02)$ \\
\hline Social support & 2.71 & 2.20 & $10.45(.001)$ & 2.32 & 2.30 & $0.02(.88)$ \\
\hline Feelings & 3.11 & 2.07 & $51.15(<.001)$ & 2.26 & 2.28 & $0.02(.90)$ \\
\hline Physical fitness & 3.32 & 2.92 & $6.20(.01)$ & 3.11 & 2.97 & $0.50(.48)$ \\
\hline Pain & 3.51 & 2.75 & $24.51(<.001)$ & 3.05 & 2.87 & $1.06(.30)$ \\
\hline Overall health & 3.66 & 2.84 & $44.39(<.001)$ & 3.11 & 2.98 & $1.07(.30)$ \\
\hline Quality of life & 3.06 & 2.51 & $22.28(<.001)$ & 2.59 & 2.63 & $0.13(.72)$ \\
\hline \multicolumn{7}{|l|}{$\begin{array}{l}\text { Health care use, number in } \\
\text { past } 2 \text { months }\end{array}$} \\
\hline Emergency services & 1.22 & 0.43 & $7.57(.006)$ & 1.04 & 0.47 & $2.78(.09)$ \\
\hline Primary care offices & 2.06 & 2.04 & $0.01(.94)$ & 1.90 & 2.08 & $0.25(.62)$ \\
\hline Specialty offices & 0.74 & 0.42 & $3.80(.052)$ & 0.72 & 0.42 & $2.47(.12)$ \\
\hline Mental health services & 0.61 & 0.34 & $2.44(.12)$ & 0.17 & 0.45 & $2.10(.15)$ \\
\hline Total ambulatory use & 4.63 & 3.22 & $5.00(.03)$ & 3.83 & 3.42 & $0.32(.57)$ \\
\hline $\begin{array}{l}\text { Hospitalizations, number } \\
\text { in past year }\end{array}$ & 1.14 & 0.51 & $5.90(.02)$ & 0.88 & 0.57 & $1.03(.31)$ \\
\hline \multicolumn{7}{|c|}{ Note: Values are multivariate analysis of variance (MANOVA) means adjusted for demographics and symptoms of mental disorders, unless otherwise noted. } \\
\hline \multicolumn{7}{|c|}{$\begin{array}{l}\text { adjusted for age, sex, and socioeconomic status; Wilk I =.797, } \mathrm{F}=5.98(P<.001) \text {. } \\
\mathrm{F}=1.58(P=.07) \text {. }\end{array}$} \\
\hline
\end{tabular}

results were significant for the model overall $(P<.001)$, with posthoc tests still revealing significantly greater impairments in all areas of functional status as well as increased use of emergency services, total ambulatory care, and hospitalizations for patients with chemical intolerance (Table 4). In MANOVA controlling for both demographics and PRIME-MD possible psychiatric disorders (Model 2), the differences in functional status and health care use were no longer significant with one exception: chemical intolerance remained significantly associated with more limitations in social activities.

\section{DISCUSSION}

\section{Key Findings}

This study found that middle-aged patients from relatively lower SES groups who attend primary care clinics have a high prevalence of chemical intolerance. Compared with healthy controls from an earlier study in the same community, San Antonio, by one of the authors (C.S.M.), ${ }^{12}$ the current patients had significantly higher scores on the QEESI subscales for chemical intolerances, other intolerances (eg, drugs, alcohol, foods), and symptom severity. The present patients, however, scored lower for masking factors that might otherwise obscure awareness of an association between chemical exposures and symptoms. In other words, the current chemically intolerant patients may be more aware of their difficulties in tolerating everyday environmental exposures than are members of the healthy population.

Moreover, comparison of the current subset of clinic patients who met criteria for elevated chemical intolerance with the non-chemically intolerant subset revealed significant odds ratios only for self-reported allergies, mood disorders, and chemical intolerance histories. From the PRIME-MD screening data, persons with high chemical intolerance had markedly elevated odds ratios for possible major depression, generalized anxiety disorder, panic disorder, and alcohol abuse disorder, as well as somatization disorder. From the self-report questionnaire, the chemically intolerant also had significantly elevated odds of family histories of gastrointestinal disorders, mood disorders, systemic lupus erythematosus, and chemical intolerance.

Although patients with chemical intolerance reported general functional impairment and increased use of emergency, ambulatory, and hospital settings, these associations largely became nonsignificant when controlling for coexisting mental disorders, suggesting that comorbid psychiatric problems may substantially 
contribute to perceived impairments and elevated health care use in persons with chemical intolerance, similar to findings in previous studies of other primary care populations in which chemical intolerance was not assessed.$^{51-58}$ Rates of alcohol abuse disorder were higher in the present chemically intolerant patients than in their unaffected counterparts, a finding that is not necessarily consistent across other samples. Although family histories for alcohol and drug problems are increased in MCS/chemical intolerance, ${ }^{21}$ many earlier studies observed increased levels of alcohol intolerance and lower levels of alcohol use in the index cases of chemical intolerance. ${ }^{12,17,28,59-62}$

At the same time, there is no evidence that treating psychiatric symptoms alone will resolve chemical intolerance. Twin studies of chronic fatigue, a common overlapping diagnosis in chemical intolerance, indicate that psychiatric illness does not fully explain the clinical picture. ${ }^{19,63}$ Previous nonclinical studies showed that psychological distress per se accounts for only a proportion of the variance in chemical intolerance scores. ${ }^{44}$ In one study, patients with MCS pointed to chemical avoidance as the single most helpful intervention. These same patients rated psychotropic medications as least helpful for their condition. ${ }^{64}$ Our study and numerous earlier studies have found increased rates of medication intolerances in the chemical intolerance population. ${ }^{12}$

Previous research has shown an association between chemical intolerance and work disability, ${ }^{3,12,14,65,66}$ problems with shopping, ${ }^{3,14}$ and difficulties with travel. ${ }^{12,14}$ Perhaps most troubling is the impact that chemical intolerance has on social functioning and relationships. ${ }^{12,14}$ In the present data, impairment in daily and social activities was independent of any associated mental disorders. Gibson et $\mathrm{al}^{67}$ found that people with chemical intolerance derive social support from involvement in chemical intolerance-related support groups and certain close relationships.

It is uncommon for primary care clinicians to recognize chemical intolerance in a given patient. Patients are not likely to report chemical intolerance as their chief complaint. The present data show that only $24 \%$ of patients who fulfilled criteria for the condition had previously received a related diagnosis. Nonetheless, earlier research found that $54 \%$ of community-dwelling people with high chemical intolerance reported at least 1 comorbid medical problem. ${ }^{3}$ In addition, patients with chemical intolerance were significantly more likely to report a family history of the condition as well. These data replicate previous findings on the familial nature of MCS and chemical intolerance. ${ }^{21,68}$

Although a detailed discussion of possible biologic mechanisms is beyond the scope of this article, laboratory studies of persons with MCS or chemical intolerance indicate that both central nervous system sensitization $^{69,70}$ and inflammatory processes ${ }^{9}$ contribute to the multisystem clinical picture. Both sensitization and chronic inflammation also play a role in the medical, psychiatric, and substance abuse conditions found at elevated rates in the personal histories, family histories, or both of patients with MCS described in the Introduction and identified in Table 2.

\section{Implications}

Our findings suggest that chemical intolerance is a common problem in primary care settings among low-SES primary care patients, but also that it often goes unrecognized and requires active investigation by the primary care physician. The presence of chemical intolerance among relatives, multiple medication intolerances, complex multisystem conditions, or a prior diagnosis of somatization disorder should raise the index of suspicion for chemical intolerance. Use of a standardized instrument such as the QEESI may be helpful in detecting chemical intolerance. If it is found, the physician should screen the patient for major depressive disorder, panic disorder, generalized anxiety disorder, and substance abuse, recognizing that these may be associated conditions, not necessarily causal.

The occupational medicine literature contains multiple reports of a higher prevalence of mood and anxiety disorders in chemically exposed workers. ${ }^{71-74}$ Chemical intolerance with multisystem symptoms, fatigue, anxiety, depression, irritability, and cognitive difficulties can also develop, after nonindustrial chemical exposures associated with home and office remodeling or extermination. ${ }^{30}$

Caress et $\mathrm{al}^{3}$ found that some people with MCS or chemical intolerance had changed various products they used, purchased air filters, moved to a different residence, or used some combination of these measures. Although avoidance of known chemical triggers is recommended, evaluation of potential psychosocial factors is also important. In addition, because those with chemical intolerance are more intolerant of many medications and medical materials, the use of nonpharmacologic approaches to treatment where feasible may be particularly important for these patients. Fox et $\mathrm{al}^{15}$ reported on the benefits of a comprehensive, holistic, multidisciplinary treatment program for chemical intolerance, which ranged from lifestyle changes and nutritional supplementation to mindfulness-based stress reduction, physical therapy, group learning, guided imagery, and psychotherapy. Such programs have been shown to reduce impairment as well as health care use and costs. ${ }^{15}$ Referring chemically intolerant patients for a comprehensive specialized program of care may thus 
be the most pragmatic and cost-effective approach for selected patients. ${ }^{15,75}$

\section{Study Limitations}

This study has several limitations. First, we used selfreport data in lieu of comprehensive but more costly and time-consuming clinical examinations and medical record reviews. Although prior research suggests that patients can accurately recall health care use over the past 2 months, the use data reported here were not verified through chart audit. Second, the PRIME-MD screen for mental disorders used in this study is not a diagnostic instrument; the actual rates of psychiatric disorders meeting DSM-IV criteria may differ. Our goal was to estimate the prevalence of chemical intolerance among primary care patients with chronic medical conditions. To reduce the risk of falsepositives on the QEESI, we screened out patients who had acute problems. Finally, because the sites used in this study predominantly served low-income, middleaged Hispanic patients, the findings may not be generalizable to other primary care populations; in fact, the prevalence of chemical intolerance was inversely related to social class in this study. Because prior studies have often focused on high-SES, white populations, however, this study contributes to our understanding of chemical intolerance in low-SES, minority primary care populations. Given their occupations and where they live, such individuals (86\% Hispanic in our sample) are far more likely than higher-SES groups to have been exposed to solvents, cleaning agents, pesticides, and other substances now clearly linked with the development of chemical intolerance and associated neuropsychiatric symptoms, via a process referred to as toxicant-induced loss of tolerance. ${ }^{76}$

In conclusion, often unrecognized, chemical intolerance is prevalent and commonly comorbid with a range of medical and psychiatric conditions in primary care settings. The QEESI is a self-report tool for busy clinicians to use in recognizing chemical intolerance symptoms and developing a more effective treatment plan. This instrument may help pinpoint potential environmental chemical, food, and drug contributors to the clinical picture and lead to improved nonpharmacologic intervention strategies. The implications for the primary care physician are that chemical intolerance is prevalent in low-income, primary care settings but must be actively sought. Patients' occupational and environmental exposures may have contributed to their condition. The presence of chemical intolerance among relatives, a history of medication intolerances/ adverse drug reactions, and multisystem symptoms including psychiatric symptoms (depression, cognitive difficulties, anxiety, panic attacks) should raise the index of suspicion for further chemical intolerance screening using the QEESI or a similar tool.

To read or post commentaries in response to this article, see it online at http://www.annfammed.org/content/10/4/357.

Key words: chemical intolerance; idiopathic environmental intolerance; multiple chemical sensitivity; psychiatric comorbidity; functional impairments; health care utilization; practice-based research

Submitted June 6, 2011; submitted, revised, September 20, 2011; accepted October 11, 2011.

Previous presentation: This paper was presented at the annual meeting of the North American Primary Care Research Group in Seattle, Washington, on November 13-17, 2010.

\section{References}

1. Caress SM, Steinemann AC. Prevalence of multiple chemical sensitivities: a population-based study in the southeastern United States. Am J Public Health. 2004;94(5):746-747.

2. Kreutzer R, Neutra RR, Lashuay N. Prevalence of people reporting sensitivities to chemicals in a population-based survey. Am J Epidemiol. 1999;150(1):1-12.

3. Caress SM, Steinemann AC, Waddick C. Symptomatology and etiology of multiple chemical sensitivities in the southeastern United States. Arch Environ Health. 2002;57(5):429-436.

4. Szarek MJ, Bell IR, Schwartz GE. Validation of a brief screening measure of environmental chemical sensitivity: the chemical odor intolerance index. J Environ Psychol. 1997;17(4):345-351.

5. Bell IR, Schwartz GE, Amend D, Peterson JM, Stini WA. Sensitization to early life stress and response to chemical odors in older adults. Biol Psychiatry. 1994;35(11):857-863.

6. Bell IR, Schwartz GE, Peterson JM, Amend D. Self-reported illness from chemical odors in young adults without clinical syndromes or occupational exposures. Arch Environ Health. 1993;48(1):6-13.

7. Bell IR, Hardin EE, Baldwin CM, Schwartz GE. Increased limbic system symptomatology and sensitizability of young adults with chemical and noise sensitivities. Environ Res. 1995;70(2):84-97.

8. De Luca C, Scordo G, Cesareo E, Raskovic D, Genovesi G, Korkina L. Idiopathic environmental intolerances (IEI): from molecular epidemiology to molecular medicine. Indian J Exp Biol. 2010;48(7):625-635.

9. De Luca C, Scordo MG, Cesareo E, et al. Biological definition of multiple chemical sensitivity from redox state and cytokine profiling and not from polymorphisms of xenobiotic-metabolizing enzymes. Toxicol Appl Pharmacol. 2010;248(3):285-292.

10. Buchwald D, Garrity D. Comparison of patients with chronic fatigue syndrome, fibromyalgia, and multiple chemical sensitivities. Arch Intern Med. 1994;154(18):2049-2053.

11. Bailer J, Witthöft M, Rist F. Psychological predictors of short- and medium term outcome in individuals with idiopathic environmental intolerance (IEI) and individuals with somatoform disorders. J Toxicol Environ Health A. 2008;71(11-12):766-775.

12. Miller CS, Prihoda TJ. A controlled comparison of symptoms and chemical intolerances reported by Gulf War veterans, implant recipients and persons with multiple chemical sensitivity. Toxicol Ind Health. 1999;15(3-4):386-397.

13. Black DW, Okiishi C, Schlosser S. A nine-year follow-up of people diagnosed with multiple chemical sensitivities. Psychosomatics. 2000;41(3):253-261.

14. Lax MB, Henneberger PK. Patients with multiple chemical sensitivities in an occupational health clinic: presentation and follow-up. Arch Environ Health. 1995;50(6):425-431. 
15. Fox RA, Joffres MR, Sampalli T, Casey J. The impact of a multidisciplinary, holistic approach to management of patients diagnosed with multiple chemical sensitivity on health care utilization costs: an observational study. J Altern Complement Med. 2007;13(2):223-229.

16. Baldwin CM, Bell IR. Increased cardiopulmonary disease risk in a community-based sample with chemical odor intolerance: implications for women's health and health-care utilization. Arch Environ Health. 1998;53(5):347-353.

17. Bell IR, Miller CS, Schwartz GE, Peterson JM, Amend D. Neuropsychiatric and somatic characteristics of young adults with and without self-reported chemical odor intolerance and chemical sensitivity. Arch Environ Health. 1996;51(1):9-21.

18. Jason LA, Taylor RR, Kennedy CL. Chronic fatigue syndrome, fibromyalgia, and multiple chemical sensitivities in a community-based sample of persons with chronic fatigue syndrome-like symptoms. Psychosom Med. 2000;62(5):655-663.

19. Ciccone DS, Natelson BH. Comorbid illness in women with chronic fatigue syndrome: a test of the single syndrome hypothesis. Psychosom Med. 2003;65(2):268-275.

20. Slotkoff AT, Radulovic DA, Clauw DJ. The relationship between fibromyalgia and the multiple chemical sensitivity syndrome. Scand J Rheumatol. 1997;26(5):364-367.

21. Black DW, Okiishi C, Gabel J, Schlosser S. Psychiatric illness in the first-degree relatives of persons reporting multiple chemical sensitivities. Toxicol Ind Health. 1999;15(3-4):410-414.

22. Bell IR, Baldwin CM, Fernandez M, Schwartz GE. Neural sensitization model for multiple chemical sensitivity: overview of theory and empirical evidence. Toxicol Ind Health. 1999;15(3-4):295-304.

23. Binkley KE, Kutcher $S$. Panic response to sodium lactate infusion in patients with multiple chemical sensitivity syndrome. J Allergy Clin Immunol. 1997;99(4):570-574.

24. Binkley K, King N, Poonai N, Seeman P, Ulpian C, Kennedy J. Idiopathic environmental intolerance: increased prevalence of panic disorder-associated cholecystokinin B receptor allele 7. J Allergy Clin Immunol. 2001;107(5):887-890.

25. Black DW, Okiishi C, Schlosser S. The lowa follow-up of chemically sensitive persons. Ann N Y Acad Sci. 2001;933:48-56.

26. Ziem G, McTamney J. Profile of patients with chemical injury and sensitivity. Environ Health Perspect. 1997;105(Suppl 2):417-436.

27. Bell IR, Bootzin RR, Schwartz GE, Baldwin CM, Ballesteros F. Differing patterns of cognitive dysfunction and heart rate reactivity in chemically-intolerant individuals with and without lifestyle changes. J Chronic Fatigue Syndr. 1999;5(2):3-25.

28. Miller CS. Chemical sensitivity: symptom, syndrome or mechanism for disease? Toxicology. 1996;111(1-3):69-86.

29. Miller CS, Prihoda TJ. The Environmental Exposure and Sensitivity Inventory (EESI): a standardized approach for measuring chemical intolerances for research and clinical applications. Toxicol Ind Health. 1999;15(3-4):370-385.

30. Miller CS, Mitzel HC. Chemical sensitivity attributed to pesticide exposure versus remodeling. Arch Environ Health. 1995;50(2):119-129.

31. Pelsser LM, Frankena K, Toorman J, et al. Effects of a restricted elimination diet on the behaviour of children with attention-deficit hyperactivity disorder (INCA study): a randomised controlled trial. Lancet. 2011;377(9764):494-503.

32. Egger J, Stolla A, McEwen LM. Controlled trial of hyposensitisation in children with food-induced hyperkinetic syndrome. [See comment]. Lancet. 1992;339(8802):1150-1153.

33. Egger J, Carter CM, Graham PJ, Gumley D, Soothill JF. Controlled trial of oligoantigenic treatment in the hyperkinetic syndrome. Lancet. 1985;1(8428):540-545.

34. Egger J, Carter CH, Soothill JF, Wilson J. Effect of diet treatment on enuresis in children with migraine or hyperkinetic behavior. Clin Pediatr (Phila). 1992;31(5):302-307.
35. Egger J, Carter CM, Wilson J, Turner MW, Soothill JF. Is migraine food allergy? A double-blind controlled trial of oligoantigenic diet treatment. Lancet. 1983;2(8355):865-869.

36. Egger J, Carter CM, Soothill JF, Wilson J. Oligoantigenic diet treatment of children with epilepsy and migraine. [See comment]. J Pediatr. 1989;114(1):51-58.

37. Dohan FC, Grasberger JC. Relapsed schizophrenics: earlier discharge from the hospital after cereal-free, milk-free diet. Am J Psychiatry. 1973;130(6):685-688.

38. Dohan FC, Grasberger JC, Lowell FM, Johnston HT Jr, Arbegast AW. Relapsed schizophrenics: more rapid improvement on a milk- and cereal-free diet. Br J Psychiatry. 1969;115(522):595-596.

39. Fiedler N, Kipen HM, DeLuca J, Kelly-McNeil K, Natelson B. A controlled comparison of multiple chemical sensitivities and chronic fatigue syndrome. Psychosom Med. 1996;58(1):38-49.

40. Staudenmayer H. Psychological treatment of psychogenic idiopathic environmental intolerance. Occup Med. 2000;15(3):627-646.

41. Bell IR. Somatization disorder: health care costs in the decade of the brain. Biol Psychiatry. 1994;35(2):81-83.

42. Grabe HJ, Baumeister SE, John U, Freyberger HJ, Völzke H. Association of mental distress with health care utilization and costs: a 5-year observation in a general population. Soc Psychiatry Psychiatr Epidemiol. 2009;44(10):835-844.

43. Aaron LA, Bradley LA, Alarcón GS, et al. Psychiatric diagnoses in patients with fibromyalgia are related to health care-seeking behavior rather than to illness. Arthritis Rheum. 1996;39(3):436-445.

44. Bell IR, Markley EJ, King DS, et al. Polysymptomatic syndromes and autonomic reactivity to nonfood stressors in individuals with selfreported adverse food reactions. J Am Coll Nutr. 1993;12(3):227-238.

45. Magill MK, Suruda A. Multiple chemical sensitivity syndrome. Am Fam Physician. 1998;58(3):721-728.

46. Hollingshead A, Redlich F. Social Class and Mental Illness. New York, NY: John Wiley; 1958.

47. Spitzer RL, Williams JBW, Kroenke $K$, et al. Utility of a new procedure for diagnosing mental disorders in primary care. The PRIMEMD 1000 study. JAMA. 1994;272(22):1749-1756.

48. Wasson J, Keller A, Rubenstein L, Hays R, Nelson E, Johnson D. Benefits and obstacles of health status assessment in ambulatory settings. The clinician's point of view. The Dartmouth Primary Care COOP Project. Med Care. 1992;30(5 Suppl):MS42-MS49.

49. Katerndahl DA, Realini JP. Use of health care services by persons with panic symptoms. Psychiatr Serv. 1997;48(8):1027-1032.

50. Brown JB, Adams ME. Patients as reliable reporters of medical care process. Recall of ambulatory encounter events. Med Care. 1992; 30(5):400-411.

51. Barsky AJ, Orav EJ, Bates DW. Somatization increases medical utilization and costs independent of psychiatric and medical comorbidity. Arch Gen Psychiatry. 2005;62(8):903-910.

52. Aaron LA, Bradley LA, Alarcón GS, et al. Psychiatric diagnoses in patients with fibromyalgia are related to health care-seeking behavior rather than to illness. Arthritis Rheum. 1996;39(3):436-445.

53. Aaron LA, Arguelles LM, Ashton S, et al. Health and functional status of twins with chronic regional and widespread pain. J Rheumatol. 2002;29(11):2426-2434. Erratum in J Rheumatol. 2002;29(12):2667. Buchwald, Dedra [corrected to Buchwald, Debra].

54. Press Y, Tandeter H, Romem P, Hazzan R, Farkash M. Depressive symptomatology as a risk factor for increased health service utilization among elderly patients in primary care. Arch Gerontol Geriatr. 2012;54(1):127-130

55. Banta JE, Andersen RM, Young AS, Kominski G, Cunningham WE. Psychiatric comorbidity and mortality among veterans hospitalized for congestive heart failure. Mil Med. 2010;175(10):732-741. 
56. Blumenfeld AM, Varon SF, Wilcox TK, et al. Disability, HRQoL and resource use among chronic and episodic migraineurs: results from the International Burden of Migraine Study (IBMS). Cephalalgia. 2011;31(3):301-315

57. Seery MD, Leo RJ, Holman EA, Silver RC. Lifetime exposure to adversity predicts functional impairment and healthcare utilization among individuals with chronic back pain. Pain. 2010;150(3):507-515.

58. Ketterer MW, Knysz W, Khandelwal A, Keteyian SJ, Farha A, Deveshwar $S$. Healthcare utilization and emotional distress in coronary artery disease patients. Psychosomatics. 2010;51(4):297-301.

59. Miller CS. Toxicant-induced loss of tolerance-an emerging theory of disease? Environ Health Perspect. 1997;105(Suppl 2):445-453.

60. Miller CS. The compelling anomaly of chemical intolerance. Ann N Y Acad Sci. 2001;933:1-23

61. Bell IR, Hardin EE, Baldwin CM, Schwartz GE. Increased limbic system symptomatology and sensitizability of young adults with chemical and noise sensitivities. Environ Res. 1995;70(2):84-97.

62. Bell IR, Schwartz GE, Peterson JM, Amend D. Symptom and personality profiles of young adults from a college student population with self-reported illness from foods and chemicals. J Am Coll Nutr. 1993;12(6):693-702.

63. Aaron LA, Herrell R, Ashton S, et al. Comorbid clinical conditions in chronic fatigue: a co-twin control study. J Gen Intern Med. 2001;16(1):24-31.

64. Gibson PR, Elms AN, Ruding LA. Perceived treatment efficacy for conventional and alternative therapies reported by persons with multiple chemical sensitivity. [See comment]. Environ Health Perspect. 2003;111(12):1498-1504.

65. Bell IR, Peterson JM, Schwartz GE. Medical histories and psycholog ical profiles of middle-aged women with and without self-reported illness from environmental chemicals. J Clin Psychiatry. 1995;56(4): 151-160.

66. Black DW, Doebbeling BN, Voelker MD, et al. Quality of life and health-services utilization in a population-based sample of military personnel reporting multiple chemical sensitivities. J Occup Environ Med. 1999;41(10):928-933.
67. Gibson PR, Cheavens J, Warren ML. Social support in persons with self-reported sensitivity to chemicals. Res Nurs Health. 1998;21(2): 103-115.

68. Miller CS. Possible models for multiple chemical sensitivity: conceptual issues and role of the limbic system. Toxicol Ind Health. 1992;8(4):181-202.

69. Fernandez M, Bell IR, Schwartz GE. EEG sensitization during chemical exposure in women with and without chemical sensitivity of unknown etiology. Toxicol Ind Health. 1999;15(3-4):305-312.

70. Bell IR, Baldwin CM, Schwartz GE. Sensitization studies in chemically intolerant individuals: implications for individual difference research. Ann N Y Acad Sci. 2001:933:38-47.

71. Sparks PJ, Simon GE, Katon WJ, Altman LC, Ayars GH, Johnson RL. An outbreak of illness among aerospace workers. West J Med. 1990;153(1):28-33.

72. Dager SR, Holland JP, Cowley DS, Dunner DL. Panic disorder precipitated by exposure to organic solvents in the work place. Am J Psychiatry. 1987;144(8):1056-1058.

73. Visser I, Wekking EM, de Boer AG, et al. Prevalence of psychiatric disorders in patients with chronic solvent induced encephalopathy (CSE). Neurotoxicology. 2011;32(6):916-922.

74. Wesseling C, van Wendel de Joode B, Keifer M, London L, Mergler D, Stallones L. Symptoms of psychological distress and suicidal ideation among banana workers with a history of poisoning by organophosphate or n-methyl carbamate pesticides. Occup Environ Med. 2010;67(11):778-784.

75. Fox R, Sampalli T, Fox J. Measuring health outcomes of a multidisciplinary care approach in individuals with chronic environmental conditions using an abbreviated symptoms questionnaire. J Multidiscip Healthc. 2008;1:97-104.

76. Ashford NA, Miller CS. Chemical Exposures: Low Levels and High Stakes, 2nd ed. New York, NY: Wiley Interscience; 1998.

\section{CORRECTIONS}

Ann Fam Med 2012;10:365. doi:10.1370/afm.1429.

Stange KS. In this issue: from communities of solution to joy. Ann Fam Med. 2012;10(3):194-195.

When referring to the article by Margolius and colleagues in the text and reference, Margolius was spelled incorrectly as Margolis

The Folsom Group. Communities of solution: the Folsom Report revisited. Ann Fam Med. 2012;10(3):250-260.

The footnote for Figure 2 shows a source of data for allied health as http://bhpr.hrsa.gov/healthworkforce/. This URL deviates from that published in the PDF of the article (http://bhpr.hrsa.gov/healthworkforce/ reports/factbook02/FB101.htm), which was not available at the time of publication. 